\title{
Aerobic Bacterial Profile and Their Antibiotic Susceptibility Patterns of Sterile Body Fluids Among Patients at Hiwot Fana Specialized University Hospital, Harar, Eastern Ethiopia
}

\author{
Tadesse Shume (D), Tewodros Tesfa (D), Shambel Mekonnen, Haftu Asmerom, Fikru Tebeje, \\ Fitsum Weldegebreal $\mathbb{D}$ \\ Department of Medical Laboratory Sciences, College of Health and Medical Science, Haramaya University, Harar, Ethiopia
}

Correspondence: Tadesse Shume, Department of Medical Laboratory Sciences, College of Health and Medical Science, Haramaya University, P.O.Box 235, Harar, Ethiopia, Email tadeshumeI5@gmail.com

Background: Infections of sterile body fluids are susceptible to serious invasive bacterial infections and critical, with high morbidity and sequelae risk. This study has not been conducted previously in eastern Ethiopia.

Objective: The present study was designed to determine the bacterial profile, associated factors, and their susceptibility to antimicrobial agents of isolates among patients with sterile body fluids at Hiwot Fana Specialized University Hospital, Harar, Eastern Ethiopia.

Methods: Hospital-based cross-sectional study was conducted from April to June 2021 among 204 patients selected using a convenient sampling technique. Data were collected using a pretested structured questionnaire. All consenting patients submitting body fluid specimens for testing at the clinical laboratory were included and analyzed using standard microbiology methods. Antimicrobial susceptibility testing was performed using the disk diffusion method and interpreted as per Clinical and Laboratory Standards Institute guidelines. Data were double entered into Epi data version 4.6, exported, and analyzed using Statistical Package for Social Science version 25. Bivariate and multivariable logistic regressions were used to assess the association between outcome and predictor variables. P-value $<0.05$ was considered to be statistically significant.

Results: The overall prevalence of bacteria among different sterile body fluid samples was $16.7 \%$ (95\% CI: $12-22 \%)$. Most of the bacterial isolates (70.6\%) were Gram-negative bacteria, mainly K. pneumoniae (26.5\%) and E. coli (20.6\%). Multidrug resistance was identified in $76.5 \%$ of the isolates. Being inpatient $(\mathrm{AOR}=3.59 ; 95 \% \mathrm{CI}: 1.52,8.51)$ and turbid appearance $(\mathrm{AOR}=4.35 ; 95 \% \mathrm{CI}$ : $1.67,11.29)$ were significantly associated with culture growth rate.

Conclusion: The prevalence of bacterial isolates in this study comprises about 17\%. Gram-negative bacteria, particularly K. pneumoniae and E. coli, were the major etiologic agents. Being inpatient and the turbid appearance of the specimen were significantly associated with the culture-positive result. Significant numbers of multidrug-resistant bacteria were isolated, mainly against beta-lactams. Therefore, culture and susceptibility testing should be an integral part of the laboratory investigation.

Keywords: sterile body fluids, bacteria, antimicrobial resistance, Eastern Ethiopia

\section{Introduction}

Sterile body fluids (SBF) are fluids in which no microbes exist as normal flora under normal conditions. However, microorganisms can invade sterile body sites ${ }^{1,2}$ causing serious invasive diseases, resulting in critical phenomenon. ${ }^{3,4}$ In response to infection, fluids may accumulate in any body cavity associated with invasive diseases, such as bacteremia, sepsis, bacterial meningitis, bacterial peritonitis, and other complications. ${ }^{5}$ These infections are serious and urgent condition that requires immediate treatment because untreated infections at sterile body sites can lead to severe potentially life-threatening infection throughout the body. ${ }^{6}$ 
Especially, infections caused by resistant pathogens are persisting to be a significant cause of severe infections across the world, with increasing morbidity and mortality rates. ${ }^{7}$ In addition, these infections caused by antimicrobial-resistant bacteria can lead to longer hospital stays, higher medical costs, and increased mortality. ${ }^{8,9}$ To a great extent, it is more prevalent in developing countries where health care services are limited, scarce resources, poor hygiene and sanitation, irrational use of antibiotics, and poverty are some of the leading causes of the development of antibiotic-resistant microbes. ${ }^{10}$ Similar to other developing countries, Ethiopia also faces similar challenges. ${ }^{11}$ Therefore, early diagnosis and appropriate antibiotic treatment are necessary to avoid and reduce complications. ${ }^{12}$

A wide range of bacterial agents have been described as sterile body fluid infections including gram-negatives, such as E. coli, Klebsiella spp.,Acinetobacter spp.,Pseudomonas spp., as well as gram-positive bacteria like Streptococci spp., Neisseria meningitidis, Enterobacter spp., Staphylococci spp., etc. ${ }^{13,14}$

In Ethiopia, there is a scarcity of data on the prevalence, associated factors, and antimicrobial susceptibility patterns of sterile body fluid infections. In particular, this topic has never been addressed in the study area. Therefore, the current study was conducted to determine the bacterial profile and antimicrobial susceptibility pattern of sterile body fluids among patients at HFSUH, Eastern Ethiopia.

\section{Materials and Methods}

\section{Study Area and Period}

This study was conducted in Harar town at HFSUH from April to June 2021. This hospital was selected because of the large and diverse population they serve. The hospital is now also a teaching facility for Health and Medical Sciences students at Haramaya University.

\section{Study Design and Population}

A hospital-based cross-sectional study was conducted among all patients who visited and admitted at HFSUH. Twohundred and four patients who submitted sterile body fluid specimens for testing to the clinical laboratories at HFSUH from the different specialty wards of the hospital and the outpatient department were included and participated. Blood samples, patients with a history of antibiotic therapy in the preceding two weeks, contaminated samples, and delayed samples for more than 2 hours were excluded.

\section{Sample Size, Sampling Technique and Procedure}

The sample size of the study was determined using a single population proportion formula by considering the magnitude of the bacterial from sterile body fluids at Tikur Anbesa Specialized Hospital, Addis Ababa, Ethiopia, with a prevalence of $14.1 \%,{ }^{13}$ a $95 \%$ confidence level, and a margin of allowable error of 5\%. To minimize the errors arising from the likelihood of non-compliance, $10 \%$ of the sample size was added. The final sample size was 204 . A convenient sampling technique was used until the required sample was reached.

\section{Data and Specimen Collection Methods}

Data were collected using pretested structured questionnaires developed after reviewing different literature. ${ }^{13,15,16}$ Following informed consent, the individual providing the sample was asked and recorded about demographic information (age, gender, marital status, residence, occupation, income, and educational status) and clinical/sample-related data (hospitalization, specimen type, area of specimen collected, and gross appearances of the specimen), which were collected through a questionnaire-guided face-to-face interview. All specimens were transported to the microbiology and processed within 2 hours of collection. ${ }^{2}$

\section{Microbiological Analysis}

Microbiological analysis was performed using a technique described by Cheesbrough tests ${ }^{17}$ to isolate and identify bacterial infection from sterile body fluids. The specimen greater than $1 \mathrm{ml}$ was centrifuged at a rate of 2500 revolutions 
per minute (rpm) for 10 minutes to concentrate on any organisms, and the sediment was then seeded for culture. However, the specimen less than $1 \mathrm{ml}$ and purulent one was inoculated directly into the culture media.

Collected specimens were cultured onto Blood agar, Mac-Conkey agar for Gram-negative bacteria and chocolate agar for fastidious organisms (HiMedia, India). The inoculated Blood agar and MacConkey agar were incubated at $35-37^{\circ} \mathrm{C}$ aerobically for 18-24 hours, and inoculated chocolate agar was incubated in a 5\% to $10 \%$ carbon dioxide-supplemented atmosphere (in a candle). Identification of grown isolates was done based on standard bacteriological techniques, such as colony morphology, Gram staining, and biochemical testing as described by Cheesbrough. ${ }^{17}$

Morphological features of the colonies such as size, shape, pigmentation, and opacity were noted and recorded. Gram staining was performed to distinguish gram-positive from gram-negative bacteria through their shape and arrangement. Biochemical characteristics of gram-positive bacteria were determined by carrying out catalase test, coagulase test, Bile Esculin test, optochin sensitivity test, Novobiocin sensitivity test, bacitracin sensitivity test, Pyrrolidonyl arylamidase (PYR) tests, mannitol test, DNase test, and hemolytic activity on blood agar. Besides, Lancefield grouping system was used for the identification of the Genus Streptococci isolates. However, indole production test, citrate utilization test, lactose and glucose fermentation test, urease test, oxidase test, lysine decarboxylase (LDC) test, methyl red/voges proskauer (MR/VP) test, motility test, and hydrogen sulfide gas production test were carried out for the identification of gram-negative bacteria. Identification of Enterobacterales and Pseudomonas bacterial isolates was confirmed using API 20E/20NE identification kit (BioMerieux, France) ${ }^{18}$

\section{Determination of the Antibiotic Sensitivity Pattern of Bacterial Isolates}

Susceptibility of isolates to antimicrobial agents of different classes was assessed by the Kirby-Bauer disk diffusion method in compliance with a commercially prepared antibiotic disc of known concentration with Clinical and Laboratory Standards Institute (CLSI) guidelines on Mueller-Hinton agar standard media ${ }^{17}$ and CLSI. ${ }^{19}$ Using a sterile wire loop, up to 5 pure colonies were picked and emulsified in $5 \mathrm{ml}$ normal saline $(0.85 \% \mathrm{NaCl})$ that matched the turbidity of the $0.5 \mathrm{McFarland}$ standard, equivalent to $1.5 \times 10^{8} \mathrm{CFU} / \mathrm{ml}$. A drop of the suspension was taken, and a sterile swab was inserted/dipped into the inoculum tube and rotated the swab against the side of the tube using firm pressure, to remove excess fluid. The suspension was swabbed and uniformly distributed over the entire surface of the Mueller Hinton agar plates using a sterile cotton-tipped applicator. Within 15 minutes of inoculation, the appropriate disks impregnated with antimicrobial agents were placed on the surface of agar plates, which were pre-inoculated with the suspension of the microorganisms being tested, and the plates were inverted for incubation to prevent the accumulation of moisture on the agar surface, which would interfere with the interpretation of test results. Finally, the plates were incubated at $37^{\circ} \mathrm{C}$ for 18 to 24 hours. Similarly, the Mueller-Hinton Agar supplemented with $5 \%$ defibrinated sheep blood at $37^{\circ} \mathrm{C}$ with; $5 \%$ carbon dioxide $(\mathrm{CO} 2)$ incubation period was used for testing fastidious organisms like streptococci and enterococci. ${ }^{20}$ After the incubation, the diameter of the inhibition zone was measured using a scaled ruler (Caliper) to the nearest millimeters and compared against the predefined values provided by CLSI guidelines. ${ }^{19}$ Using the Interpretative chart based on CLSI 2020 guidelines, the zone sizes of each antibiotic were interpreted, and the isolate was reported as sensitive (S), intermediate (I), or resistant (R). ${ }^{19}$ In this study, multi-drug resistance (MDR) was defined as non-susceptibility to at least one agent in three or more antimicrobial categories. ${ }^{21}$ Oxacillin (methicillin) susceptibility to Staphylococcus aureus and Coagulase-negative Staphylococci was interpreted using $30 \mu \mathrm{g}$ cefoxitin as a surrogate test for Methicillin-resistant Staphylococcus aureus (MRSA). ${ }^{19}$

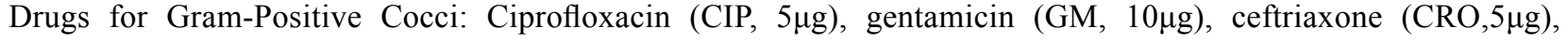

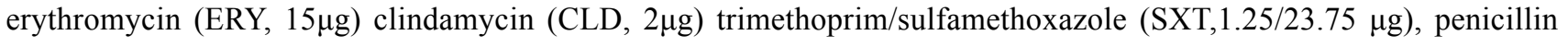

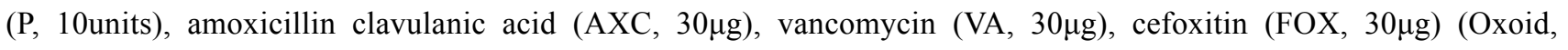
LTD, UK).

Drugs for Gram-Negative Bacilli: Ampicillin (AMP, $10 \mu \mathrm{g}$ ), amoxicillin-clavulanic acid (AMC, $30 \mu \mathrm{g}$ ), ceftriaxone (CRO, $30 \mu \mathrm{g}$ ), ceftazidime (CAZ, $30 \mu \mathrm{g}$ ), amikacin (AMK, $30 \mu \mathrm{g}$ ), gentamicin (GM, $10 \mu \mathrm{g}$ ), meropenem (MEM, 10 $\mu \mathrm{g}$ ) ciprofloxacin (CIP, $5 \mu \mathrm{g}$ ), trimethoprim/sulfamethoxazole (SXT,1.25/23.75 $\mu \mathrm{g}$ ) (Oxoid, LTD, UK). These antibacterial discs were selected based on pathogen, local availability, and CLSI recommendations. 


\section{Quality Assurance}

The questionnaire was initially prepared in the English language and was translated into local languages (Afan Oromo and Amharic) and translated back to English by language experts to assure its consistency. Five percent of the questionnaire (5\%) was pretested at Jugel General Hospital to check its consistency and understandability before the actual data collection. The data was double entered by two data clerks into Epi-data. The consistency of the entered data was cross-checked by comparing the two separately entered data.

To maintain the quality of the data, standard operating procedures were followed in the preparation of media and drug susceptibility testing. As an internal quality control, uninoculated media (negative control) were incubated and must remain clear to check for sterility. American Type Culture Collection (ATCC) reference strains, such as Escherichia coli (ATCC 25922), Pseudomonas aeruginosa (ATCC 27853), and/or Staphylococcus aureus (ATCC 25923), were used as positive controls (for culture and monitoring the quality of the reagents). Known strains from United Kingdom External Quality Assessment Scheme (UKNEQA): E. coli (UKNEQA 6453) and S. aureus (UKNEQA 5958) were used for drug susceptibility testing as well. These standard control strains were obtained from the Child Health and Mortality Prevention Surveillance (CHAMPS) project. The inoculum density of the bacterial suspension was standardized to the $0.5 \mathrm{McFarland}$ standard to perform antibiotic susceptibility testing.

\section{Data Processing and Analysis}

All questionnaires were checked for completeness. The collected data were double entered, cleaned using Epi-data (version 4.6) and exported to the Statistical Package for Social Sciences software (SPSS) version 25 for further cleaning and analysis. Descriptive statistical tools were used to summarize the findings. Logistic regression models through bivariate and multivariate logistic regression were used to predict the relationship between dependent and independent variables; to identify factors associated with culture-positive rates. Variables with a p-value $\leq 0.25$ in bivariate logistic regression analysis were moved to a multivariable logistic regression analysis model, which accounts for potential confounding and identification of independent predictors. Crude odds ratio (COR) and adjusted odds ratio (AOR) with their $95 \%$ confidence interval (CI) were used to determine the significance of the predictors. Variables with a p-value less than 0.05 in multivariable analysis were taken as significant predictors. In addition, p-values were calculated using fisher's exact test for some variables. The assumption of multivariate logistic regression was checked using Hosmer and Lemeshow goodness-of-fit-test, and a p-value $>0.05$ was considered a good fit.

\section{Ethical Consideration}

Ethical clearance was obtained from Haramaya University Institutional Health Research Ethics Review Committee of the College of Health and Medical Sciences (IHRERC) before the commencement of the study. This study was conducted in accordance with the Declaration of Helsinki. Informed consent was obtained from each participant before the commencement of data collection. To maintain confidentiality, independent code numbers were given to each study participant. Besides, both study participants and data collectors used sanitizer and worn face masks to protect them from COVID-19.

\section{Result}

\section{Socio-Demographic Characteristics}

In this study, a total of 204 study patients were recruited and participated. Among enrolled patients, a majority (63.7\%) of study participants were males, $32.4 \%$ were unable to read and write, $66.2 \%$ were rural residents, and $63.8 \%$ were married. The median and interquartile range of the age of the study participants was 33 and 56, respectively. Nearly half $(47 \%)$ of the study participants were in the age group of less than 20 years (Table 1).

\section{Clinical and Sample-Related Characteristics}

A total of 204 body fluid samples were collected and investigated. These data showed that more than half of the processed samples were CSF (52.0\%) followed by pleural fluid (29.9\%). Out of a total of 34 (16.7\%) positive cases, half 
Table I Socio-Demographic Character of the Study Participants of Sterile Body Fluid Infections at Hiwot Fana Specialized University Hospital, Harar, Eastern Ethiopia, 2021

\begin{tabular}{|c|c|c|c|}
\hline Variables & Category & Frequency & $\%$ \\
\hline \multirow[t]{4}{*}{ Age } & $\leq 20$ & 96 & 47.1 \\
\hline & $21-40$ & 16 & 7.8 \\
\hline & $4 I-60$ & 35 & 17.2 \\
\hline & $\geq 61$ & 57 & 27.9 \\
\hline \multirow[t]{2}{*}{ Sex } & Male & 130 & 63.7 \\
\hline & Female & 74 & 36.3 \\
\hline \multirow[t]{2}{*}{ Residence } & Urban & 69 & 33.8 \\
\hline & Rural & 135 & 66.2 \\
\hline \multirow[t]{5}{*}{ Marital Status } & Under age* & 77 & 37.7 \\
\hline & Single & 29 & 22.8 \\
\hline & Married & 81 & 63.8 \\
\hline & Widowed & 5 & 4.0 \\
\hline & Divorced & 12 & 9.4 \\
\hline \multirow[t]{6}{*}{ Educational status } & Pre-school & 62 & 30.4 \\
\hline & Unable to read and write & 66 & 32.4 \\
\hline & Read and write & 19 & 9.3 \\
\hline & Primary & 23 & 11.3 \\
\hline & Secondary/High school & 16 & 7.8 \\
\hline & College and above & 18 & 8.8 \\
\hline \multirow[t]{7}{*}{ Occupation } & Government employee & 43 & 21.1 \\
\hline & Labor worker & 2 & 1.0 \\
\hline & Student & 37 & 18.1 \\
\hline & House wife & 8 & 3.9 \\
\hline & Farmer & 80 & 39.2 \\
\hline & Merchant & 26 & 12.7 \\
\hline & Other & 8 & 3.9 \\
\hline \multirow[t]{3}{*}{ Monthly income } & $\leq 1500$ & 110 & 53.9 \\
\hline & $1600-3000$ & 83 & 40.7 \\
\hline & $\geq 3100$ & 11 & 5.4 \\
\hline
\end{tabular}

Note: *Non-candidates for marital status.

$(50 \%)$ of the isolates were identified from CSF sample. The higher culture-positive cases were found in the inpatient sample $(61.8 \%)$ and a larger proportion $(56 \%)$ of the isolates were from turbid appearance (Table 2$)$.

\section{Prevalence of Bacterial Isolates}

From a total of 204 specimens, 34 were culture-positive, which yielded an overall prevalence of $16.7 \%$ (95\% CI: $12 \%$ to $22 \%)$. As shown in Figure 1, the highest frequency and distribution were shown by gram-negative bacteria $(24 / 34$, $70.6 \%)$. Among these, K. pneumoniae $(9 / 24,37.5 \%)$ and E. coli $(724,29.2 \%)$ were the most predominantly isolated gram-negative bacteria, while Gram-positive cocci constituted the remaining 10 cases (10/34, 29.4\%). Of these, S. aureus (4/10, 40\%) and Enterococcus spp. (4/10, 40\%) were the main isolates.

\section{Associated Factors}

In bivariate regression analysis, age, patient setting, and appearance of the specimen showed a significant association at a $p$-value of $\leq 0.25$ and were considered as candidates for multivariate logistic regression. Through a multivariable analysis, being inpatient and turbid appearance were significantly associated with culture-positivity rates at p-value $<0.05$ after adjusting for confounding factors. 
Table 2 Total and Positive Cases of Clinical and Sample-Related Characteristics of Sterile Body Fluid Infection Among Patients at Hiwot Fana Specialized University Hospital, Harar, Eastern Ethiopia, 2021

\begin{tabular}{|c|c|c|c|c|}
\hline Variables & Category & Growth N (\%) & No Growth N (\%) & Total N (\%) \\
\hline \multirow[t]{5}{*}{ Specimen type } & CSF & $17(16)$ & $89(84)$ & $106(52.0)$ \\
\hline & Synovial & - & $3(100)$ & $3(1.5)$ \\
\hline & Pleural & $12(19.7)$ & $49(80.3)$ & $61(29.8)$ \\
\hline & Peritoneal & $5(14.7)$ & $29(85.3)$ & $34(16.7)$ \\
\hline & Total & $34(16.7)$ & $170(83.3)$ & $204(100)$ \\
\hline \multirow[t]{3}{*}{ Patient setting } & Inpatient & $21(22.8)$ & $71(77.2)$ & $92(45.1)$ \\
\hline & Outpatient & $13(\mid \mathrm{I} .6)$ & $99(88.4)$ & $112(54.9)$ \\
\hline & Total & $34(16.7)$ & $170(83.3)$ & $204(100)$ \\
\hline \multirow[t]{7}{*}{ Ward/outpatient unit } & Gynecology-obs & I (25) & $3(75)$ & $4(2.0)$ \\
\hline & Pediatrics & II (I7.2) & $53(82.8)$ & $64(31.3)$ \\
\hline & Medical & $21(17.4)$ & $100(82.6)$ & $12 \mid(59.3)$ \\
\hline & Surgical & I (I4.3) & $6(85.7)$ & $7(3.4)$ \\
\hline & $\mathrm{NICU}$ & - & $3(100)$ & $3(1.5)$ \\
\hline & Isolation center & - & $5(100)$ & $5(2.5)$ \\
\hline & Total & $34(16.7)$ & $170(83.3)$ & $204(100)$ \\
\hline \multirow[t]{4}{*}{ Specimen appearance } & Clear & $8(8)$ & $92(92)$ & $100(49.0)$ \\
\hline & Turbid & $19(26.8)$ & $52(73.2)$ & 71 (34.8) \\
\hline & Bloody & $2(13.3)$ & $13(86.7)$ & $15(7.4)$ \\
\hline & Other* & $5(27.8)$ & $13(72.2)$ & $18(8.8)$ \\
\hline Overall total & & 34 (16.7) & $130(83.3)$ & $204(100)$ \\
\hline
\end{tabular}

Note: *Purulent, yellowish.

In the case of the patient setting, inpatients were 3.59 times ( $\mathrm{AOR}=3.59 ; 95 \% \mathrm{CI}: 1.52,8.51 ; \mathrm{P}=0.004)$ more likely to be infected compared to those of outpatients. The odds of being culture-positive rate increased by 4.35 times (AOR $=$ 4.35; 95\% CI: $1.67,11.29 ; \mathrm{P}=0.003)$ for those patients who had the turbid appearance of the specimen rather than the counter parts. Even if a high positivity rate was observed among participants with an age group above 60 years, there was no significant difference between the age group and culture-positivity rate $(\mathrm{p}=0.14)$ (Table 3$)$.

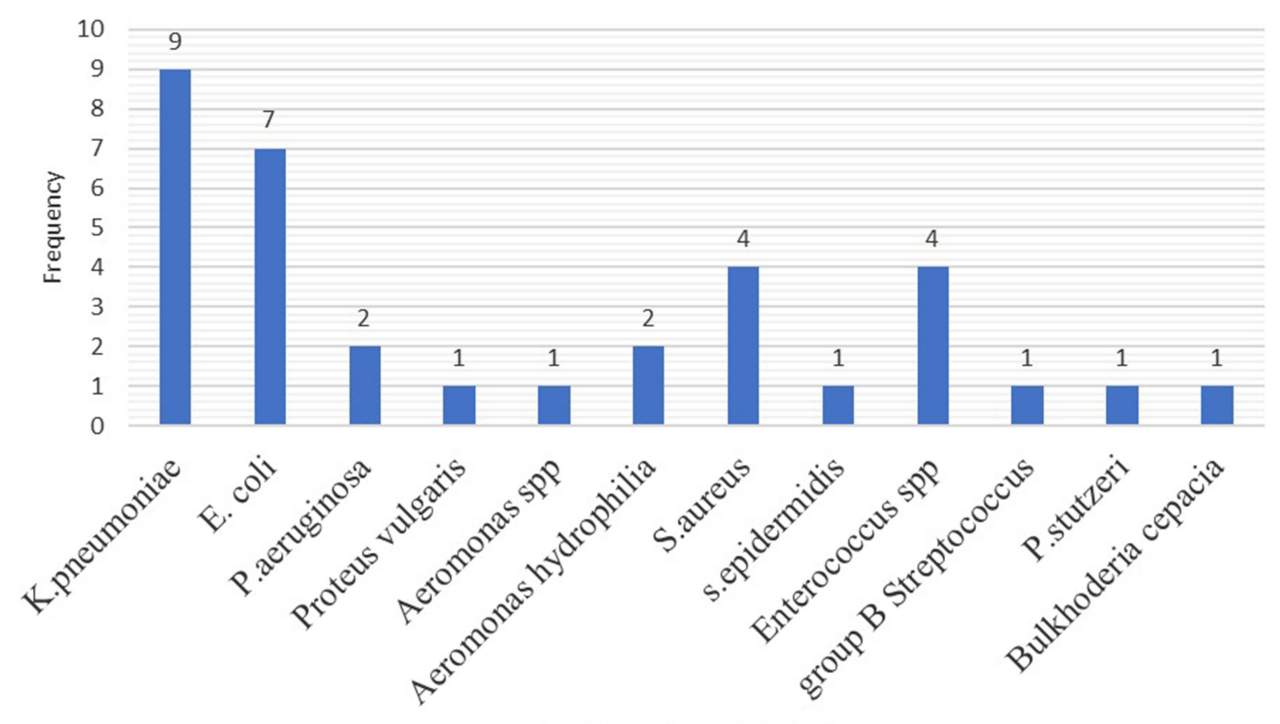

Isolated pathogenic bacteria

Figure I Bacterial isolates from patients diagnosed with sterile body fluid infections at HFSUH, Harar, Eastern Ethiopia at Hiwot Fana Specialized University Hospital, Harar, Eastern Ethiopia, 202I. 
Table 3 Bivariate and Multivariate Analysis of Factors Associated with Bacterial Infections from Sterile Body Fluids at Hiwot Fana Specialized University Hospital, Harar, Eastern Ethiopia, 2021

\begin{tabular}{|c|c|c|c|c|c|c|c|}
\hline \multirow{3}{*}{ Variables } & \multirow{3}{*}{ Category } & \multirow{2}{*}{\multicolumn{2}{|c|}{ Culture Growth N (\%) }} & \multicolumn{2}{|l|}{ Bivariant Analysis } & \multicolumn{2}{|c|}{ Multivariable Analysis } \\
\hline & & & & \multirow[t]{2}{*}{ COR $(95 \% \mathrm{Cl})$} & \multirow[t]{2}{*}{ P-value } & \multirow[t]{2}{*}{ AOR (Cl 95\%) } & \multirow[t]{2}{*}{ P-value } \\
\hline & & Yes & No & & & & \\
\hline Gender & $\begin{array}{l}\text { Male } \\
\text { Female }^{\circledR}\end{array}$ & $\begin{array}{l}23(17.7) \\
\mathrm{II}(15)\end{array}$ & $\begin{array}{l}107(82.3) \\
63(85)\end{array}$ & $1.23(0.56,2.69)$ & 0.60 & & \\
\hline Residence & $\begin{array}{l}\text { Rural } \\
\text { Urban }^{\circledR}\end{array}$ & $\begin{array}{l}24(17.8) \\
10(14.5)\end{array}$ & $\begin{array}{l}I I I(82.2) \\
59(85.5)\end{array}$ & $1.27(0.57,2.85)$ & 0.55 & & \\
\hline Age group & $\begin{array}{l}\leq 20 \\
4 I-60 \\
\geq 6 I \\
2 I-40^{\circledR}\end{array}$ & $\begin{array}{l}\mathrm{I} \mid(\mathrm{I} \mid .5 \%) \\
9(25.7 \%) \\
\mathrm{I} 3(22.8 \%) \\
\mathrm{I}(6.3 \%)\end{array}$ & $\begin{array}{l}85(88.5 \% 0 \\
26(74.3 \%) \\
44(77.2 \%) \\
15(93.7 \%)\end{array}$ & $\begin{array}{l}1.94(0.23,16.16) \\
5.19(0.59,45.09) \\
4.43(0.53,36.80)\end{array}$ & $\begin{array}{l}0.54 \\
0.135 \\
0.168\end{array}$ & $\begin{array}{l}2.28(0.25,20.91) \\
5.67(0.59,55.31) \\
5.62(0.61,51.97)\end{array}$ & $\begin{array}{l}0.46 \\
0.13 \\
0.13\end{array}$ \\
\hline Patient type & $\begin{array}{l}\text { Inpatient } \\
\text { Outpatient }^{\circledR}\end{array}$ & $\begin{array}{l}21(22.8 \%) \\
13(11.6 \%)\end{array}$ & $\begin{array}{l}7 I(77.2 \%) \\
99(88.4 \%)\end{array}$ & $2.25(1.058,4.796)$ & 0.035 & $3.59(1.52,8.51)$ & $0.004^{*}$ \\
\hline Specimen type & $\begin{array}{l}\text { Synovial } \\
\text { Plueral } \\
\text { Ascites } \\
\text { CSF }\end{array}$ & $\begin{array}{l}- \\
12(19.7) \\
5(14.7) \\
17(16)\end{array}$ & $\begin{array}{l}3(100) \\
49(80.3) \\
29(85.3) \\
89(84)\end{array}$ & $\begin{array}{l}\text { Fisher's exact test } \\
\text { F-test }=0.68\end{array}$ & $P=0.89$ & & \\
\hline $\begin{array}{l}\text { Appearance of } \\
\text { specimen }\end{array}$ & $\begin{array}{l}\text { Turbid } \\
\text { Bloody } \\
\text { Other } \\
\text { Clear }{ }^{\circledR}\end{array}$ & $\begin{array}{l}19(26.8 \%) \\
2(13.3 \%) \\
5(27.8 \%) \\
8(8 \%)\end{array}$ & $\begin{array}{l}52(73.2 \%) \\
13(86.7 \%) \\
13(72.2 \%) \\
92(92 \%)\end{array}$ & $\begin{array}{l}4.20(1.72,10.27) \\
1.77(0.34,9.26) \\
4.42(1.27,15.59)\end{array}$ & $\begin{array}{l}0.002 \\
0.499 \\
0.021\end{array}$ & $\begin{array}{l}4.35(1.67,11.29) \\
1.37(0.25,7.5) \\
3.66(0.96,13.9)\end{array}$ & $\begin{array}{l}0.003 * \\
0.714 \\
0.058\end{array}$ \\
\hline
\end{tabular}

Note: *Statistically significant.

Abbreviations: COR, crude odds ratio; AOR, adjusted odds ratio; $\mathrm{Cl}$, confidence interval; ${ }^{\circledR}$, reference category.

\section{Antimicrobial Susceptibility Testing}

A drug sensitivity test was performed for all ${ }^{34}$ bacterial isolates. Isolates have shown various resistance and susceptibility patterns against different antibiotics that were tested. The antimicrobial profile of gram-negative bacteria, ciprofloxacin $(87.5 \%)$ and meropenem (83.3\%) were found to be the most effective drugs against gram-negative isolates. Also, they showed higher sensitivity to amikacin (75\%). However, resistance to ampicillin (87.5\%), and third-generation cephalosporins such as ceftriaxone (75\%) and ceftazidime (75\%) were shown among gram-negative isolates.

Among antibiograms of gram-positive bacteria, they $(n=10 / 34)$ were resistant to penicillin $(8 / 10,80 \%)$, ceftriaxone $(8 / 10,80 \%)$, and erythromycin $(6 / 10,60 \%)$. Meanwhile, amoxicillin-clavulanic acid and trimethoprim-sulfamethoxazole exhibited moderate activity (50\%) against gram-positive isolates. In the susceptibility pattern of $S$. aureus, trimethoprimsulfamethoxazole was most effective against all $S$. aureus isolates. By contrast, all $S$. aureus isolates were resistant to cefoxitin, which indicates methicillin resistant S. aureus (MRSA). And ampicillin, ceftriaxone, and penicillin were also ineffective against $S$. aureus. In addition, all isolates of Enterococcus species were resistant to vancomycin, penicillin, ceftriaxone, and trimethoprim sulfamethoxazole. Moreover, the antibiotic susceptibility patterns of the recovered Grampositive and Gram-negative isolates are shown in Tables 4 and 5, respectively.

In general, multi-drug resistance (MDR) (resistance to at least one agent in $\geq 3$ classes of antimicrobials) was identified in $76.4 \%$ (95\% CI: $60 \%$ to $92 \%$ ) of the isolates. Out of the 34 isolates, 26 isolates $(76.4 \%)$ were MDR. Among these MDR isolates, 19 isolates (73\%) were Gram-negative and 7 isolates (27\%) were Gram-positive. Based on this finding, penicillin, ampicillin, ceftriaxone, ceftazidime, gentamicin, and trimethoprim-sulfamethoxazole showed a high rate of resistance.

\section{Discussion}

Microbial invasion of normally sterile parts of the body can cause systemic illness. ${ }^{22}$ It is a life-threatening emergency and any delay in treatment may result in death. In addition, any microorganisms found where no resident microbiota is 
Table 4 Antimicrobial Susceptibility Pattern of a Gram-Negative Bacterial Isolate from Sterile Body Fluid Samples at Hiwot Fana Specialized University Hospital, Harar, Eastern Ethiopia, 2021

\begin{tabular}{|c|c|c|c|c|c|c|c|c|c|c|}
\hline \multicolumn{11}{|c|}{ Antimicrobial Classes } \\
\hline \multicolumn{2}{|l|}{$N=24$} & \multicolumn{2}{|c|}{ Penicillins } & \multicolumn{2}{|c|}{ Cephalosporin } & \multirow{2}{*}{$\begin{array}{l}\text { Fluoroquinolones } \\
\text { CPR }\end{array}$} & \multirow{2}{*}{$\begin{array}{l}\text { Sulfonamides } \\
\text { SXT }\end{array}$} & \multirow{2}{*}{$\begin{array}{l}\text { Carbapenem } \\
\text { MEM }\end{array}$} & \multicolumn{2}{|c|}{ Aminoglycosides } \\
\hline Isolated Organism & Pattern & AMP & AXC & CRO & CTZ & & & & AMK & GN \\
\hline \multirow[t]{3}{*}{ K. pneumoniae $(n=9)$} & $\mathrm{s}$ & 1 & 4 & 2 & 1 & 8 & 1 & 8 & 4 & 4 \\
\hline & 1 & - & 4 & I & - & - & 5 & 1 & 3 & 1 \\
\hline & $\mathrm{R}$ & 8 & I & 6 & 8 & I & 3 & - & 2 & 4 \\
\hline \multirow[t]{3}{*}{ E. coli $(n=7)$} & $\mathrm{s}$ & - & 2 & - & - & 7 & 1 & 6 & 7 & 1 \\
\hline & I & - & 4 & - & - & - & 2 & - & - & - \\
\hline & $\mathrm{R}$ & 7 & 1 & 7 & 7 & - & 4 & 1 & & 6 \\
\hline \multirow[t]{3}{*}{ P. aeruginosa $(\mathrm{n}=2)$} & $\mathrm{s}$ & - & - & - & - & 1 & - & - & 2 & - \\
\hline & 1 & - & - & - & - & - & - & - & - & - \\
\hline & $\mathrm{R}$ & 2 & 2 & 2 & 2 & I & 2 & 2 & - & 2 \\
\hline \multirow[t]{3}{*}{ P. stutzeri $(\mathrm{n}=1)$} & s & - & - & - & - & I & - & 1 & I & 1 \\
\hline & 1 & 1 & - & - & - & - & - & - & - & - \\
\hline & $\mathrm{R}$ & - & 1 & 1 & I & - & $\mathrm{I}$ & - & - & - \\
\hline \multirow[t]{3}{*}{ Aeromonas sp. $(\mathrm{n}=\mathrm{I})$} & $\mathrm{s}$ & - & - & - & - & 1 & 1 & 1 & - & - \\
\hline & 1 & 1 & 1 & 1 & 1 & - & - & - & 1 & - \\
\hline & $\mathrm{R}$ & - & - & - & - & - & - & - & - & 1 \\
\hline \multirow[t]{3}{*}{ P. vulgaris $(n=1)$} & $\mathrm{s}$ & - & 1 & 1 & 1 & 1 & 1 & 1 & 1 & 1 \\
\hline & 1 & - & - & - & - & - & - & - & - & - \\
\hline & $\mathrm{R}$ & 1 & - & - & - & - & - & - & - & - \\
\hline \multirow[t]{3}{*}{ A. hydrophilia $(\mathrm{n}=2)$} & $\mathrm{s}$ & - & 2 & - & - & 1 & - & 2 & & 1 \\
\hline & 1 & - & - & 1 & 2 & - & I & - & - & - \\
\hline & $R$ & 2 & - & 1 & - & 1 & 1 & - & - & 1 \\
\hline \multirow[t]{3}{*}{ B. cepacia $(\mathrm{n}=1)$} & s & - & 1 & - & 1 & 1 & - & 1 & I & - \\
\hline & 1 & - & - & - & - & - & 1 & - & - & - \\
\hline & $R$ & 1 & - & 1 & - & - & - & - & - & 1 \\
\hline \multirow[t]{3}{*}{ Total $(24, \%)$} & s & $\mathrm{I}(4.2)$ & $10(41.7)$ & $3(12.5)$ & $3(12.5)$ & $21(87.5$ & $4(16.7)$ & $20(83.3)$ & $18(75)$ & $8(33.3)$ \\
\hline & 1 & $2(8.3)$ & $9(37.5)$ & $3(12.5)$ & $3(12.5)$ & - & $9(37.5)$ & $I(4.2)$ & $4(16.7)$ & I (4.2) \\
\hline & $\mathrm{R}$ & $21(87.5)$ & $5(20.8)$ & $18(75)$ & $18(75)$ & $3(12.5)$ & $1 \mathrm{II}(45.8)$ & $3(12.5)$ & $2(8.3)$ & $15(62.5)$ \\
\hline
\end{tabular}

Abbreviations: AMP, ampicillin; CRO, ceftriaxone; AMC, amoxicillin-clavulanic acid; GN, gentamicin; SXT, trimethoprim-sulfamethoxazole; CTZ, ceftazidime: MEM, meropenem; AMK, amikacin; CPR, ciprofloxacin; S, sensitive; I, intermediate; $\mathrm{R}$, resistant. 
Table 5 Antimicrobial Susceptibility Patterns of a Gram-Positive Bacterial Isolate from Sterile Body Fluid Samples at Hiwot Fana Specialized University Hospital, Harar, Eastern Ethiopia, 2021

\begin{tabular}{|c|c|c|c|c|c|c|c|c|c|c|c|c|}
\hline \multicolumn{13}{|c|}{ Antimicrobial Classes } \\
\hline \multicolumn{2}{|l|}{$N=10$} & \multicolumn{4}{|c|}{ Penicillins } & \multirow{2}{*}{$\begin{array}{l}\text { Cephalosporin } \\
\text { CRO }\end{array}$} & \multirow{2}{*}{$\begin{array}{l}\text { Macrolides } \\
\text { ERY }\end{array}$} & \multirow{2}{*}{$\begin{array}{l}\text { Fluoroquinolones } \\
\text { CPR }\end{array}$} & \multirow{2}{*}{$\begin{array}{l}\text { Sulfonamides } \\
\text { SXT }\end{array}$} & \multirow{2}{*}{$\begin{array}{l}\text { Glycopeptides } \\
\text { VA }\end{array}$} & \multirow{2}{*}{$\begin{array}{l}\text { Aminoglycosides } \\
\text { GN }\end{array}$} & \multirow{2}{*}{$\begin{array}{l}\text { Lincosamides } \\
\text { CLN }\end{array}$} \\
\hline Isolates (N) & Pattern & $\mathbf{P}$ & AMP & AXC & FOX & & & & & & & \\
\hline \multirow[t]{3}{*}{ S. aureus $(n=4)$} & $\mathrm{s}$ & - & - & 3 & - & - & - & 2 & 4 & NA & - & 3 \\
\hline & 1 & - & 1 & 1 & - & - & 1 & - & - & & 2 & 1 \\
\hline & $\mathrm{R}$ & 4 & 3 & - & 4 & 4 & 3 & 2 & - & & 2 & - \\
\hline \multirow[t]{3}{*}{ Enterococcus spp. $(n=4)$} & $\mathrm{s}$ & - & - & - & NA & - & - & - & - & - & NA & - \\
\hline & I & - & 1 & 2 & NA & - & 1 & I & - & - & NA & 1 \\
\hline & $\mathrm{R}$ & 4 & 3 & 2 & NA & 4 & 3 & 3 & 4 & 4 & NA & 3 \\
\hline \multirow[t]{3}{*}{ S. epidermidis $(n=1)$} & $\mathrm{s}$ & - & 1 & 1 & 1 & 1 & 1 & 1 & - & NA & - & 1 \\
\hline & 1 & 1 & - & - & - & - & - & - & 1 & NA & - & - \\
\hline & $\mathrm{R}$ & - & - & - & - & - & - & - & - & NA & 1 & - \\
\hline \multirow[t]{3}{*}{ S. agalactiae $(n=1)$} & S & I & 1 & I & NA & I & I & I & I & - & - & - \\
\hline & 1 & - & - & - & NA & - & - & - & - & 1 & - & I \\
\hline & $\mathrm{R}$ & - & - & - & NA & - & - & - & - & - & 1 & - \\
\hline \multirow[t]{3}{*}{ Total $(n=10, \%)$} & $S$ & $1(10$ & $2(20)$ & $5(50)$ & I (10) & $2(20$ & $2(20$ & $4(40)$ & $5(50)$ & - & - & $4(40)$ \\
\hline & 1 & $\mathrm{I}(10$ & $2(20)$ & $2(20)$ & - & - & $2(20$ & $I(10)$ & $I(10)$ & $\mathrm{I}(20$ & 2(33) & $3(30)$ \\
\hline & $R$ & $8(80$ & $6(60)$ & $2(20)$ & $4(90)$ & $8(80$ & $6(60$ & $5(50)$ & $4(40)$ & $4(80$ & $4(67)$ & $3(30)$ \\
\hline
\end{tabular}

Abbreviations: NA, not applicable; AMP, ampicillin; SXT, trimethoprim-sulfamethoxazole; CRO, ceftriaxone; AMC, amoxicillin-clavulanic acid GN, gentamicin; VA, vancomycin; P, penicillin; CPR, ciprofloxacin; FOX, cefoxitin; ERY, erythromycin; CLN, clindamycin; S, sensitive; I, intermediate; R, resistant. 
present must be considered significant. ${ }^{23}$ More recently, the effectiveness of currently available antibiotics is decreasing globally as a result of increasing resistant strains. As a result, infection caused by resistant agents is difficult; it becomes impossible to treat. ${ }^{24,25}$

In the present study, the overall prevalence of bacterial pathogens was $17 \%$ (95\% CI: $12-22 \%)$. This finding is consistent with previous studies from Mekelle, Ethiopia (20.2\%), ${ }^{16}$ India $(22 \%),{ }^{26}$ and Brazil $(21.3 \%) .{ }^{27}$ In contrast, it is higher as compared to reports from Addis Ababa, Ethiopia (11.5\%) ${ }^{28}$ and Nepal $(10.7 \%)$, ${ }^{29}$ but lower than other studies in India $(36 \%)^{30}$ and Turkey $(25 \%) .{ }^{31}$ These variations can be attributed to differences, in sample processing/laboratory technique (molecular technique versus conventional methods), and the practice of infection control. ${ }^{12}$ Other explanations could be variation in sample size and duration of the study.

In this study, the most frequently isolated microorganisms were gram-negative bacteria (70.6\%). A similar finding is reported from previous studies in India $(71 \%)^{32}$ and Addis Ababa, Ethiopia (74.6\%). ${ }^{28}$ In contrast, studies from Mekelle, Ethiopia, ${ }^{16}$ Turkey, ${ }^{31}$ and India ${ }^{33,34}$ reported that gram-positive bacteria were found to be the most common isolates. This difference could be due to different hospital-acquired infections, and different standard infection control precautions. ${ }^{35,36}$ Besides, different sample sizes and study areas could be attributed to the difference.

In general, Klebsiella pneumoniae and Escherichia coli were the bacterial species most frequently isolated, causing sterile bodies infection in this study (47\%), which is similar to the findings that have been reported in previous studies done in India, ${ }^{32}$ Addis Ababa, Ethiopia, ${ }^{28}$ and Nepal. ${ }^{29}$ This finding can be explained by their distinctive structure of gram-negative bacteria leading to increasingly resistant to most available antibiotics, or the opportunistic nature of organisms. ${ }^{37,38}$

In the analysis, being inpatient and the turbid appearance of the sample had shown a significant effect $(\mathrm{p}<0.05)$ on the culture-growth rate. Significant association between patient type (hospitalization) and culture-growth $(\mathrm{p}<0.05)$ was observed. The odds of culture-growth were 3.59 times higher in inpatient cases compared to those of outpatients $(\mathrm{p}=$ 0.004). The higher rate of culture-positive result among inpatients could be due to secondary sources of infection (cirrhosis, surgical procedures, trauma) and low immune status due to any underlying medical conditions (burn, transplant surgery, and intensive care support. ${ }^{39}$ Besides, probably due to nosocomial acquired infections at the time of admission. ${ }^{36,40}$

In relation to the appearance of the specimens, the results indicated that the appearance of the specimens was associated with a culture-positivity rate $(\mathrm{P}=0.003)$. The turbid appearance of the specimen was 4.35 times more likely to be culture-positive than counterpart. This finding is in agreement with the previous studies in Ethiopia. ${ }^{13}$ The high detection of bacteria in the turbid appearance can partially be attributed to the rapid changes in the physiology and immunology of the patient as a result of bacteria. Thus, turbidity may indicate the presence of microbes, or a buildup of white blood cells or proteins. ${ }^{2}$

In this study, ciprofloxacin (87.5\%), meropenem (83.3\%), and amikacin (75\%) in the fluoroquinolone, carbapenem, and aminoglycoside class of antibiotics, respectively, were found to be most effective against gram-negative isolates. However, $\beta$-lactam antibiotics such as ampicillin (12.5\%) and third-generation cephalosporins $(25 \%)$ were the least effective antibiotics against those of gram-negative agents. This finding is comparable to previous studies in Nepal, ${ }^{29}$ India, ${ }^{32}$ and Ethiopia. ${ }^{13,16}$ The increased rate of beta-lactam drug resistance can be possibly correlated with the frequent use of these antibiotics, easy availability, the practice of self-medication, limited diagnostic facilities, inappropriate antibiotic use, and the issuance of prescriptions without susceptibility data have been considered as the factors associated with this phenomenon. ${ }^{24,41}$ In addition, antibiotic resistance can occur naturally such as efflux pumps, alteration of the drug-binding site, membrane permeability, and due to degradation enzymes. ${ }^{24}$

However, a higher prevalence of resistance to the commonly prescribed beta-lactam drugs was observed in the present study among gram-positive isolates, where (80\%) of the isolates were resistant to penicillin and ceftriaxone, but half $(50 \%)$ of the isolates were sensitive to amoxicillin-clavulanic acid and trimethoprim-sulfamethoxazole. Similarly, high levels of resistance to beta-lactam agents were reported from previous study in Ethiopia ${ }^{13,16}$ and India. ${ }^{32}$ This $^{24}$ finding could be explained by the production of beta-lactamase and/or the presence of mobile-resistant factors. ${ }^{24}$ In addition, prescribing frequency as a result of wide availability of beta-lactams, type antibiotic use, and irrational use of antibiotics could also be the factors for increasing antibiotic resistance. ${ }^{10,42}$ 
Furthermore, all $S$. aureus isolates $(\mathrm{n}=4,100 \%)$ in this study were methicillin resistant (MRSA), which is higher compared to the report from other countries like India, 36.6\%, ${ }^{33}$ Nepal $(30 \%),{ }^{29}$ and Ethiopia $(36.4 \%) .{ }^{28}$ This could be due to geographic variation, differences in infection control practice, and difference in treatments used. ${ }^{43}$

In the present study, high rates of multi-drug resistance (MDR) (76.4\%) (95\% CI: 60\% to 92\%) were reported in the current study, particularly against penicillins and third-generation cephalosporin class of antibiotics, and aminoglycosides specifically gentamicin. A similar prevalence rate of MDR was reported from studies in Addis Ababa, Ethiopia (75\%) ${ }^{44}$ and Mekelle, Ethiopia (90\%). ${ }^{16}$ But higher than Nepal (30\%). ${ }^{29}$ There could be many explanations for this difference and increased prevalence including: different bacterial strains, geographic variation, patients' awareness towards the use of the antimicrobials, the difference in infection control practice, the difference in antibiotic prescribing policies, easy availability of drugs without a prescription, and indiscriminate/prolonged use of common antibiotics lead to rapid and extensive spread of antimicrobial resistance. ${ }^{7,45}$

\section{Limitations of the Study}

The culture positivity of sterile body fluid was relatively low as the etiology of sterile fluid infections also included anaerobic bacteria, which were not identified in this study. Also, the risk of false-negative results in agarbased culture media is high because only a small number of microorganisms may be present in the specimens. ${ }^{31,46}$ To overcome this drawback, innovative techniques using enrichment media and polymerase chain reaction (PCR) are very helpful and recommended. ${ }^{27}$

\section{Conclusion and Recommendations}

A variety of gram-positive, as well as gram-negative organisms, were documented, which yielded $17 \%$. Most notably, Klebsiella pneumoniae and Escherichia coli were the leading causative agents for sterile body area infection. Being inpatient and turbid appearance of the specimen was significantly associated with the culture-growth rate of the infection. The majority (76.5\%) of the isolates showed multidrug resistance, especially against beta-lactams and gentamicin, which suggests one of the most important public health problems currently.

Culture and susceptibility testing should be an integral part of routine laboratory tests for the management of infections in patients, and the choice of drugs should be based on results of sensitivity testing. The antibiotic sensitivity profile of this study suggests that ciprofloxacin and amikacin can be the choice of drugs for the infections. However, Beta-lactam antibiotics such as third-generation cephalosporins, ampicillin, and penicillin should be used based on microbiological evidence. The careful prescribing practice or rational use of antibiotics based on sensitivity testing result is needed to stop the tendency to increase antibiotic resistance. Besides, great care should be given to inpatients, as they are more vulnerable to infections at sterile sites and tissues.

The present study was conducted on a limited number of samples; this may not reflect the entire scenarios of the study. This highlights the need for further studies to be conducted on larger sample sizes.

\section{Acknowledgment}

We acknowledged Haramaya University Colleges of Health and Medical Sciences Institutional Health Research Ethical Review Committee for giving the ethical clearance. We also thank study participants and all individuals who have in one way or another contributed to the completion of this research.

\section{Author Contributions}

All authors made a significant contribution to the work reported, whether that is in the conception, study design, execution, acquisition of data, analysis, and interpretation, or in all these areas; took part in drafting, revising or critically reviewing the article; gave final approval of the version to be published; have agreed on the journal to which the article has been submitted; and agree to be accountable for all aspects of the work.

\section{Funding}

This research data collection finance was covered by Haramaya university postgraduate directorate. 


\section{Disclosure}

Authors have no conflicts of interest.

\section{References}

1. Altun O. Rapid microbiological diagnosis of infections in sterile body fluids including blood; 2020.

2. Strasinger SK, Di Lorenzo MS. Urinalysis and body fluids: FA Davis; 2014.

3. Grif K, Heller I, Prodinger W, Lechleitner K, Lass-Flörl C, Orth D. Improvement of detection of bacterial pathogens in normally sterile body sites with a focus on orthopedic samples by use of a commercial 16S rRNA broad-range PCR and sequence analysis. J Clin Microbiol. 2012;50 (7):2250-2254. doi:10.1128/JCM.00362-12

4. Badiee P. Evaluation of human body fluids for the diagnosis of fungal infections. Bio Med Res Int. 2013;2013. doi:10.1155/2013/698325

5. Dellinger RP, Levy MM, Rhodes A, et al. Surviving Sepsis Campaign: international guidelines for management of severe sepsis and septic shock, 2012. Intensive Care Med. 2013;39(2):165-228. doi:10.1007/s00134-012-2769-8

6. Kristianti GH, Suwarba IGNM, Mahalini DS, Gustawan IW, Utama IMGDL. Bacteria and antibiotic susceptibility patterns of cerebrospinal fluid isolated in children with bacterial meningitis at Sanglah Hospital, Bali from 2016 to 2018. Clin Neurol Neurosurg. 2020;4(3):51. doi:10.11648/j. cnn.20200403.12

7. Aslam B, Wang W, Arshad MI, et al. Antibiotic resistance: a rundown of a global crisis. Infect Drug Resist. 2018;11:1645. doi:10.2147/IDR. S173867

8. Sodani S, Hawaldar R. Bacteriological profile and antibiotic sensitivity pattern in various body fluids-A retrospective study. Indian J Microbiol Res. 2020;7(1):1-58

9. Marston HD, Dixon DM, Knisely JM, Palmore TN, Fauci AS. Antimicrobial resistance. JAMA. 2016;316(11):1193-1204. doi:10.1001/ jama.2016.11764

10. Iskandar K, Molinier L, Hallit S, et al. Drivers of antibiotic resistance transmission in low-and middle-income countries from a "one health" perspective - a review. Antibiotics. 2020;9(7):372. doi:10.3390/antibiotics9070372

11. Dugassa J, Shukuri N. Review on antibiotic resistance and its mechanism of development. J Health Med Nurs. 2017;1(3):1-17.

12. Fleischmann-Struzek C, Goldfarb DM, Schlattmann P, Schlapbach LJ, Reinhart K, Kissoon N. The global burden of paediatric and neonatal sepsis: a systematic review. Lancet Respir Med. 2018;6(3):223-230. doi:10.1016/S2213-2600(18)30063-8

13. Teklehymanot F, Legese MH, Desta K. Bacterial profile and their antimicrobial resistance patterns from body fluids at Tikur Anbessa Specialized Hospital, Addis Ababa, Ethiopia. Biol Med. 2017;9(5):408. doi:10.4172/0974-8369.1000408

14. Oordt-Speets AM, Bolijn R, van Hoorn RC, Bhavsar A, Kyaw MH. Global etiology of bacterial meningitis: a systematic review and meta-analysis. PLoS One. 2018;13(6):e0198772. doi:10.1371/journal.pone.0198772

15. Bwisa L. Antimicrobial susceptibility patterns of bacteria isolated from sterile sites: cerebral spinal fluid, blood, peritoneal fluid, pleural fluid and synovial fluid at Kenyatta National Hospital; 2014.

16. Tsegay E, Hailesilassie A, Hailekiros H, Niguse S, Saravanan M, Abdulkader M. Bacterial isolates and drug susceptibility pattern of sterile body fluids from tertiary hospital, Northern Ethiopia: a four-year retrospective study. J Pathog. 2019;2019. doi:10.1155/2019/5456067

17. Cheesbrough M. District Laboratory Practice in Tropical Countries, Part 2. Cambridge university press; 2005.

18. AL-Joda BMS, Jasim AH. Biochemical testing revision for identification several kinds of bacteria. JUBPAS. 2021;29(2):168-176.

19. CLSI. Performance Standards for Antimicrobial Susceptibility Testing. 30th ed. PA: Clinical and Laboratory Standards Institute Wayne; 2020.

20. Kirby B. Kirby-Bauer disk diffusion susceptibility test protocol. Am Soc Microbiol. 2009;66(208):55-63.

21. Magiorakos A-P, Srinivasan A, Carey R, et al. Multidrug-resistant, extensively drug-resistant and pandrug-resistant bacteria: an international expert proposal for interim standard definitions for acquired resistance. Clin Microbiol Infect. 2012;18(3):268-281. doi:10.1111/j.1469-0691.2011.03570.x

22. Díaz J, García P, de la Barra R, Gasep J, Levican J, Quiroga T. Utilidad de la citocentrifugación en el diagnóstico bacteriológico microscópico de fluidos corporales. Revista chilena de infectología. 2002;19(3):167-173.

23. Vetter E, Torgerson C, Feuker A, et al. Comparison of the BACTEC MYCO/F Lytic bottle to the isolator tube, BACTEC Plus Aerobic F/bottle, and BACTEC Anaerobic Lytic/10 bottle and comparison of the BACTEC Plus Aerobic F/bottle to the Isolator tube for recovery of bacteria, mycobacteria, and fungi from blood. J Clin Microbiol. 2001;39(12):4380-4386. doi:10.1128/JCM.39.12.4380-4386.2001

24. Chokshi A, Sifri Z, Cennimo D, Horng HJ. Global contributors to antibiotic resistance. J Glob Infect Dis. 2019;11(1):36. doi:10.4103/jgid. jgid_110_18

25. Levy SB, Marshall B. Antibacterial resistance worldwide: causes, challenges and responses. Nat Med. 2004;10(12):S122-S9. doi:10.1038/nm1145

26. Medegar K, Harshika YK, Patil BA, NR Smita. A study on bacteriological profile and antimicrobial resistance pattern from various body fluids of patients attending the tertiary care hospital, KIMS, Hubli. Indian J Microbiol Res. 2018;5(4):530-534. doi:10.18231/2394-5478.2018.0107

27. Daur AV, Klimak JF, Cogo LL, Botão GD, Monteiro CLB. Dalla Costa LM. Enrichment methodology to increase the positivity of cultures from body fluids. Braz J Infect Dis. 2006;10:372-373.

28. Ebrahim S, Rahman NMM, Imtiaz R. Bacterial profile and antimicrobial susceptibility pattern of isolates recovered from sterile body fluids referred to the national reference laboratory. Lancet Planet Health. 2020;4(1):e379-e380. doi:10.1016/S2542-5196(20)30175-3

29. Shrestha LB, Bhattarai NR, Khanal B. Bacteriological profile and antimicrobial susceptibility pattern among isolates obtained From body fluids. $J$ Nepal Health Res Counc. 2019;17(2):173-177. doi:10.33314/jnhrc.v0i0.1656

30. Deb A, Mudshingkar S, Dohe V, Bharadwaj R. Bacteriology of body fluids with an evaluation of enrichment technique to increase culturepositivity. J Evol Med Dent Sci. 2014;3(72):15230-15238. doi:10.14260/jemds/2014/4050

31. Çetin ES, Kaya S, Demirci M, Aridogan BC. Comparison of the BACTEC blood culture system versus conventional methods for culture of normally sterile body fluids. Adv Ther. 2007;24(6):1271-1277. doi:10.1007/BF02877773

32. Sandhya EMA, Savio R, Dutta A, Das B, Sharma T, Hazarika M. A study of bacteriological profile of sterile body fluids in a tertiary care hospital. Int J Sci Res. 2019;8(S11):41-45. doi:10.15373/22778179

33. Vishalakshi B, Hanumanthappa P, Krishna S. A study on aerobic bacteriological profile of sterile body fluids. Int J Curr Microbiol Appl Sci. 2016;5 (5):120-126. doi:10.20546/ijcmas.2016.505.013 
34. Pal N, Sharma R, Rishi S, Vyas L. Optimum time to detection of bacteria and yeast species with BACTEC 9120 culture system from blood and sterile body fluids. J Lab Physicians. 2009;1(2):069-72.

35. Mehta Y, Gupta A, Todi S, et al. Guidelines for prevention of hospital acquired infections. Indian J Crit Care Med. 2014;18(3):149. doi:10.4103/ 0972-5229.128705

36. Peleg AY, Hooper DC. Hospital-acquired infections due to gram-negative bacteria. N Engl J Med. 2010;362(19):1804-1813. doi:10.1056/ NEJMra0904124

37. Butel M-J, Waligora-Dupriet A-J, Wydau-Dematteis S. The developing gut microbiota and its consequences for health. J Dev Orig Health Dis. 2018;9(6):590-597. doi:10.1017/S2040174418000119

38. Krieg NR, Manual H. Systematic bacteriology. Williams Baltimore; 1984.

39. Sanon M. Hazards of Hospitalization. In: Geriatric Practice. Springer; 2020:403-423.

40. Poorabbas B, Mardaneh J, Rezaei Z, et al. Nosocomial infections: multicenter surveillance of antimicrobial resistance profile of staphylococcus aureus and gram negative rods isolated from blood and other sterile body fluids in Iran. Iran J Microbiol. $2015 ; 7(3): 127$.

41. Tacconelli E, Sifakis F, Harbarth S, et al. Surveillance for control of antimicrobial resistance. Lancet. Infect Dis. 2018;18(3):e99-e106. doi:10.1016/ S1473-3099(17)30485-1

42. Frieri M, Kumar K, Boutin A. Antibiotic resistance. J Infect Public Health. 2017;10(4):369-378. doi:10.1016/j.jiph.2016.08.007

43. Rouf M, Nazir A. Aerobic bacteriological profile and antimicrobial sensitivity pattern of bacteria isolated from sterile body fluids: a study from a tertiary care hospital in North India. Microbiol Res Int. 2019;1-10. doi:10.9734/mrji/2019/v28i130123

44. Ebrahim S, Abera A, Terfe K, et al. Bacterial profile and antimicrobial susceptibility pattern of isolates recovered from sterile body fluids referred to the national reference laboratory. Ethiop J Health Dev Nutr. 2020;4(1):1-5.

45. World Health Organization. Antimicrobial Resistance: Global Report on Surveillance. World Health Organization; 2014.

46. Sorlin P, Mansoor I, Dagyaran C, Struelens MJ. Comparison of resin-containing BACTECTM Plus Aerobic/F* medium with conventional methods for culture of normally sterile body fluids. J Med Microbiol. 2000;49(9):787-791. doi:10.1099/0022-1317-49-9-787

Infection and Drug Resistance

Dovepress

\section{Publish your work in this journal}

Infection and Drug Resistance is an international, peer-reviewed open-access journal that focuses on the optimal treatment of infection (bacterial, fungal and viral) and the development and institution of preventive strategies to minimize the development and spread of resistance. The journal is specifically concerned with the epidemiology of antibiotic resistance and the mechanisms of resistance development and diffusion in both hospitals and the community. The manuscript management system is completely online and includes a very quick and fair peer-review system, which is all easy to use. Visit http://www.dovepress.com/testimonials.php to read real quotes from published authors.

Submit your manuscript here: https://www.dovepress.com/infection-and-drug-resistance-journal 